\title{
Epidemiology of Chlamydia trachomatis endocervical infection in a previously unscreened population in Rome, Italy, 2000 to 2009
}

V Marcone (valentinamarcone@libero.it) ${ }^{1}$, N Recine ${ }^{2}$, C Gallinelli ${ }^{1}$, R Nicosia $^{1}$, M Lichtner $^{3}$, A M Degener ${ }^{4}$, F Chiarini $^{1}$, E Calzolari², V Vullo ${ }^{1}$

1. Department of Public Health and Infectious Diseases, Sapienza University, Rome, Italy

2. Department of Obstetric and Gynaecological Sciences and Urologic Sciences, Sapienza University, Rome, Italy

3. Department of Infectious Diseases, Sapienza University, Polo Pontino, Rome, Italy

4. Department of Molecular Medicine, Sapienza University, Rome, Italy

Marcone V, Recine N, Gallinelli C, Nicosia R, Lichtner M, Degener AM, Chiarini F, Calzolari E, Vullo V. Epidemiology of Chlamydia trachomatis endocervical infection in a previously unscreened population in Rome, Italy, 2000 to 2009 . Euro Surveill. 2012;17(25): pii=20203. Available online: http://www.eurosurveillance.org/

ViewArticle.aspx?Articleld=20203

Article submitted on 07 October 2011 / published on 21 June 2012

As reliable data on Chlamydia trachomatis infection in Italy are lacking and as there is no Italian screening policy, epidemiological analyses are needed to optimise effective strategies for surveillance of the infection in the country. We collected data from 6,969 sexually active women aged 15 to 55 years who underwent testing for endocervical $C$. trachomatis infection at the Cervico-Vaginal Pathology Unit in the Department of Gynaecology and Obstetrics of Sapienza University in Rome between 2000 and 2009. The mean prevalence of $C$. trachomatis endocervical infection during this period was $5.2 \%$. Prevalence over time did not show a linear trend. Univariate analysis demonstrated a significant association of infection with multiple lifetime sexual partners, younger age ( $\$ 40$ years), never having been pregnant, smoking, use of oral contraceptives, and human papillomavirus and Trichomonas vaginalis infections. Multivariate stepwise logistic regression showed that $T$. vaginalis infection, age under 20 years and more than one lifetime sexual partner remained significantly associated with $C$. trachomatis infection in the final model. Prevalence of $C$. trachomatis in this study was high, even among women aged 25-39 years (5.1\%): our data would suggest that a C. trachomatis screening policy in Italy is warranted, which could lead to a more extensive testing strategy.

\section{Introduction}

Chlamydia trachomatis endocervical/urethral infection, caused by serotypes $\mathrm{D}$ to $\mathrm{K}$ is the most common bacterial, treatable sexually transmitted infection worldwide $[1,2]$. As up to $80 \%$ of cases are asymptomatic, C. trachomatis can be spread unknowingly and remains largely undiagnosed $[1,2]$. The prevalence of the infection in Europe varies according to the population, setting, country, resource allocation for surveillance and prevention and national reporting system, if there is one. A systematic review of $C$. trachomatis infection among asymptomatic unscreened European women showed that the prevalence ranged from $1.7 \%$ (among women aged $15-40$ years in the United Kingdom in the mid-1990s) to $17 \%$ (among women aged 15-55 years in France in the late 1980s) and was more than $5 \%$ in the majority of the countries examined $[3,4]$. More recently the European Centre for Disease Prevention and Control (ECDC) described surveys from seven countries, estimating a population prevalence of $1.4-3.0 \%$ in people aged 18-44 years [5]. They also reported that overall trends over time across Europe appeared to be increasing, from 1990 to 2009, although data were not available from Bulgaria, Czech Republic, France, Germany, Italy, Liechtenstein and Portugal [6]. Moreover, the organisation of the control of $C$. trachomatis infection varied widely, with many countries having no organised activities until 2009 [7].

Pelvic inflammatory disease, tubal sterility or infertility, newborn eye infection or pneumonia and, although controversial, sperm pathology, male sterility and spontaneous abortion or preterm labour, are wellknown complications of untreated $C$. trachomatis infection [8-14].

Since treating complications is costly in both psychosocial and financial terms, and is often unsuccessful [15], screening is critical for the early detection and treatment of uncomplicated $C$. trachomatis infection, the control of the overall prevalence of the infection in the population and thus the reduction of transmission and finally for the reduction of treatment costs.

C. trachomatis screening programmes exist in only two European countries (England and the Netherlands) and in the United States: they are opportunistic or pro-active and are mostly directed at young women aged under 25 years $[7,16]$. Sweden, although lacking 
nationally organised screening programmes, is the first country in the world to offer testing for $C$. trachomatis infection, treatment and partner notification - all free of charge - throughout the country. It is also the first to have a national diagnostic and reporting system [5]. In these four countries, after substantial decreases in complication rates of $C$. trachomatis infection at the end of the 1980 s and early 1990s, further decreases in pelvic inflammatory disease and ectopic pregnancy rates after 2000 were observed [7,16-20].

Unfortunately, reliable and recent data concerning C. trachomatis control in Italy are lacking, except for those in studies such as that of the Italian MEGIC Group (Multicentre Epidemiology Group for Investigation of Chlamydia trachomatis) that reported a prevalence of C. trachomatis infection of $3.9 \%$ among 1,321 asymptomatic women [21] or that of the STD Surveillance Working Group, which described 809 female incident cases from mainly dermatology and venereology departments and a few gynaecological departments between 1991 and 1996 [22].

There is no screening policy for $C$. trachomatis infection in Italy. A national women's health report released in 2008 suggested for the first time that women should be tested for $C$. trachomatis when they have their first cervical smear test [23]. In order to understand if a screening strategy would be appropriate, the prevalence of the infection needs to be ascertained and there needs to be a preliminary analysis of the epidemiological variables in the population at risk, as well as a surveillance network. No existing epidemiological model can be applied to a different population without analysis and adjustment. New, larger epidemiological analyses are therefore needed in Italy to plan specific and effective strategies for the surveillance and screening of $C$. trachomatis infection in the country. The purpose of this study was to investigate the prevalence of $C$. trachomatis endocervical infection and its determinants in a large population of sexually active women aged $15-55$ years attending an outpatient service of a cervico-vaginal pathology unit in Rome over a 10-year period.

\section{Methods}

\section{Patient population}

Between January 2000 and December 2009, a total of 7,620 women (aged 13-58 years) attending the outpatient service of the Cervico-Vaginal Pathology Unit in the Department of Gynaecology and Obstetrics of Sapienza University in Rome were examined for genitourinary symptoms or routine gynaecological examination.

A team of gynaecologists collected socio-demographic and behavioural data, as well as clinical data, for each woman during this time, using our model of clinical record taking for sexually transmitted infections - a structured questionnaire. The data were archived as digital files.

The self-administered, structured, paper questionnaire comprised 25 questions on socio-demographic characteristics, sexual behaviour, reproductive history, and tobacco, alcohol and drug use.

Testing for $C$. trachomatis infection, along with testing for human papillomavirus (HPV) and N. gonorrhoeae infection and vaginal wet mount examination, was offered to all sexually active women presenting to the Unit.

Women who refused to be tested for $C$. trachomatis and/or to answer the questionnaire and/or were not sexually active were excluded from the study $(n=651)$.

According to these criteria, a total of 6,969 sexually active women aged 15-55 years who were tested for cervical C. trachomatis infection were enrolled. The women were categorised as symptomatic if they presented with either dysuria or pelvic pain or both (symptoms typical of $C$. trachomatis infection). Women not exhibiting either of these symptoms were classified as asymptomatic. They were then further categorised according to whether they were seeking care for family planning, infertility routine gynaecological examination or matters related to pregnancy.

All participating women gave written informed consent. The research was carried out in compliance with the Declaration of Helsinki [24] and was approved by the local ethics committee (reference number 148/11, 2022). Data were stored and managed according to Italian privacy rules [25].

\section{Examinations performed}

On a scheduled visit, during the gynaecological examination, an unmoistened sterile speculum was inserted into vagina, so that vaginal walls, fornices and cervix could be evaluated for any erythema and colour and viscosity of any discharge. The $\mathrm{pH}$ of the vaginal walls was measured using colorimetric paper. For wet mount examinations, vaginal fluor samples were collected from lateral fornices by a wooden Ayre's spatula, mixed first with saline and then with $10 \%$ potassium hydroxide, on two different slides, and immediately observed under a phase contrast microscope [26].

A 'whiff test' using $10 \%$ potassium hydroxide was performed for each sample in order to detect abnormal amine production by anaerobes [27].

Wet mount examination allowed the vaginal microflora (predominance of lactobacillary morphotypes) to be assessed and Trichomonas vaginalis to be detected (in order to investigate coexisting sexually transmitted infections). In addition, we also looked for bacterial vaginosis-associated clue cells, aerobic 
vaginitis-associated pleomorphic bacteria, yeasts and white blood cells.

Samples were taken from the endocervix for detection of $C$. trachomatis and from the ecto-endocervix for detection of HPV DNA, as described below.

\section{Detection of microorganisms}

\section{Chlamydia trachomatis}

Endocervical swabs were tested for the presence of $C$. trachomatis using the BD ProbeTec ET System (Becton, Dickinson and Company, United States). These assays amplify C. trachomatis DNA in separate wells and monitor inhibition of amplification for each specimen using strand displacement amplification and detection by fluorescent energy transfer probes, producing a method-other-than-acceleration (MOTA) score for each specimen The original algorithm involved retesting specimens with MOTA scores between 2000 and 9999. A negative repeat result (MOTA score 2000 ) was considered indeterminate [28].

\section{Human papillomavirus}

DNA was extracted from cervical samples using QIAampTissue Kit (Qiagen, Italy) and then genotyped by sequencing a 450-base pair fragment amplified from the L1 region of HPV DNA [29]. Sequence homology was determined using BLAST and ClustalW programs.

Neisseria gonorrhoeae

Identification of $N$. gonorrhoeae was carried out by growth on media selective for pathogenic Neisseria species (Oxoid) incubated for up to 48 hours in $5-10 \%$ $\mathrm{CO}_{2}$ at $35-37^{\circ} \mathrm{C}$. Colonies obtained were identified by API NH (bioMérieux) [30].

\section{Statistical analysis}

The chi-square test was used to analyse contingency tables; the t-test was used to compare means and odds ratios (ORs), with 95\% confidence intervals (Cls), in order to measure the strength of association between C. trachomatis infection and behavioural and clinical characteristics and age.

We used the Cochran-Armitage test to assess the possibility of a linear trend in the observed patterns for number of lifetime sexual partners and increasing age.

Statistical tests were considered significant if $p$ was 0.05 or less. A stepwise backward logistic regression analysis, entering the variables significantly associated with $C$. trachomatis infection, was used to assess the effect of more than one variable at a time and to identify possible confounding factors in the range of test values under consideration. Statistical analysis was performed using SPSS version 18.0.
A total of $366(5.2 \%)$ of the 6,969 women sexually active women enrolled in the study tested positive for C. trachomatis endocervical infection (Table 1).

Prevalence of $C$. trachomatis infection by year is shown in the Figure: the $p$ value for the chi-square statistic was not statistically significant $(p=0.938)$ (the chi-square test for the resulting $2 \times 10$ contingency table tested the null hypothesis of no association against the alternative hypothesis of an association of some sort). Thus prevalence and time appeared not to be associated and were not expected to have a linear correlation over the study period.

A total of 4,620 (66\%) of the women were asymptomatic for C. trachomatis infection: 256 (5.5\%) of them tested positive. This prevalence was slightly higher than that in the 2,349 symptomatic women $(4.7 \%)$, but the difference was not statistically significant $(p=0.1289)$. Of the 366 women who were positive for $C$. trachomatis infection, 256 (70\%) were asymptomatic.

Prevalence was also slightly higher among women without clinical signs of infection $(238 / 4,328 ; 5.5 \%$ compared with those with signs $(128 / 2,641 ; 4.8 \%)$, but this difference was also not statistically significant $(p=0.2362)$.

Univariate analysis of sexual and reproductive history and of age (Tables 1 and 2) highlighted a significant association of $C$. trachomatis infection with age under 40 years, having never been pregnant, smoking, use of oral contraceptives and multiple lifetime sexual partners: women with two to four partners had a slightly higher risk of infection (in comparison with women who had had one partner); women with five to nine partners had double the risk; having had more than nine partners was linked to a threefold higher risk. The $p$ value for the Cochran-Armitage test (p<o.0001) suggested an underlying positive linear trend between number of lifetime sexual partners and prevalence of infection.

Comparison of the prevalence of $C$. trachomatis infection in stratified age groups with that in women over 49 years of age showed that teenage women aged $15^{-19}$ years had the highest increased risk of infection (OR: 4.55 (95\% Cl: 1.90-10.89); $p=0.0002$ ) and that the odds ratios for the remaining strata declined with increasing age. The $p$ value for the Cochran-Armitage test ( $p<0.0001)$ suggested an underlying negative linear trend between age and prevalence of infection.

Further univariate analysis showed that the prevalence of the infection was similar (no statistical significance) whatever the reason for seeking care (Table 2). Condom use was not found to be associated with $C$. trachomatis infection.

The frequency of $C$. trachomatis infection was significantly higher among patients who were also infected

\section{Results}


with HPV (OR: 5.50 (95\% Cl: 4.39-6.89)) and T. vaginalis (OR: 4.97 (95\% Cl: 2.57-9.59)) (Table 3).

Multivariate stepwise logistic regression analysis shows that after backwards elimination, T. vaginalis infection (OR: 3.23 (95\% Cl: 1.61-6.46); $p=0.001$ ), age 15-19 years (OR: 2.33 (95\% Cl: $1.02-5.31) ; p=0.04$ ) and more than one lifetime sexual partner (OR: 1.50 (95\% $\mathrm{Cl}$ : 1.21-1.87); $\mathrm{p}=0.000)$ remained significantly associated with $C$. trachomatis infection in the final model.

We found no cases of gonorrhoea among the first thousand patients referred to the clinic and systematically screened. We then tested $C$. trachomatis-positive cases only, if they showed symptoms or signs of cervicitis: none were positive for $N$. gonorrhoeae.

\section{Discussion}

To the best of our knowledge, this is the first study reporting on the epidemiology of $C$. trachomatis infection in Italy in a large sample of a diverse group of women over a long period of time. The mean prevalence of the infection was high (5.2\%) and showed no linear trend over time. The prevalence in asymptomatic women was higher than that observed in 1990 by the MEGIC group (5.5\% vs $3.9 \%$, respectively) [21]. In symptomatic women and in those seeking care for infertility the prevalence in our study $(4.7 \%$ and $4.9 \%$ respectively) was similar to that reported by the same group (5.0\% and 5.4\%, respectively) [21]. These findings may reflect the lack of control and screening activities in Italy.

We also found a high prevalence of $C$. trachomatis infection in pregnant women (5.3\%), i.e. those seeking obstetric care (Table 2 ) which has not been described in Italy and suggests we should consider screening in pregnancy according to CDC guidelines [16]. This strategy could also reduce the rate of obstetric complications due to $C$. trachomatis infection.

Two of the variables independently associated with C. trachomatis infection in our study, younger age and multiple lifetime sexual partners (particularly more

\section{TABLE 1}

Univariate analysis of age and sexual and reproductive history of women tested for Chlamydia trachomatis infection, Cervico-Vaginal Pathology Unit, Sapienza University, Rome, Italy, 2000-2009 (n=6,969)

\begin{tabular}{|c|c|c|c|c|c|}
\hline \multirow[b]{2}{*}{ Characteristic } & \multicolumn{3}{|c|}{ Tested for C. trachomatis endocervical infection } & \multirow[b]{2}{*}{ Odds ratio ${ }^{\mathrm{a}}(95 \% \mathrm{Cl})$} & \multirow{2}{*}{$\begin{array}{c}\text { P value } \\
\text { (t-test statistic) }^{\mathrm{b}}\end{array}$} \\
\hline & $\begin{array}{c}\text { Number } \\
\text { positive (\%) }\end{array}$ & $\begin{array}{c}\text { Number } \\
\text { negative }^{\mathrm{a}}\end{array}$ & Total $^{\mathrm{a}}$ & & \\
\hline \multicolumn{6}{|l|}{ Mean age in years } \\
\hline $15-19$ & $9(10.8)$ & 74 & 83 & $4.55(1.90-10.89)$ & 0.0002 \\
\hline $20-24$ & $71(7.8)$ & 835 & 906 & $3.18(1.78-5.70)$ & 0.0000 \\
\hline $25-29$ & $86(5.6)$ & 1,441 & 1,527 & $2.23(1.26-3.96)$ & 0.0049 \\
\hline $30-34$ & $84(5.2)$ & 1,519 & 1,603 & $2.07(1.17-3.68)$ & 0.0113 \\
\hline $35-39$ & $61(5.1)$ & 1,125 & 1,186 & $2.03(1.12-3.66)$ & 0.0166 \\
\hline $40-44$ & $29(4.2)$ & 656 & 685 & $1.65(0.87-3.16)$ & $0.1242^{c}$ \\
\hline $45-49$ & $12(2.7)$ & 429 & 441 & $1.05(0.48-2.29)$ & $0.9084^{c}$ \\
\hline$\geq 50-55$ & $14(2.6)$ & 524 & 538 & 1 Reference & - \\
\hline Mean age per category & 32.0 years & 34.4 years & 33.2 years & $\begin{array}{l}\text { Difference (those positive vs } \\
\text { those negative): }-2.4\end{array}$ & $\begin{array}{c}0.001 \\
(\mathrm{t}=-4.610)\end{array}$ \\
\hline \multicolumn{6}{|l|}{ Number of lifetime sexual partners } \\
\hline 1 & $89(3.4)$ & 2,508 & 2,597 & 1 Reference & - \\
\hline 2 & $71(5.6)$ & 1,191 & 1,262 & $1.68(1.22-2.31)$ & 0.0013 \\
\hline 3 & $57(5.1)$ & 1,063 & 1,120 & $1.51(1.08-2.12)$ & 0.0167 \\
\hline 4 & $41(5.5)$ & 702 & 743 & $1.65(1.13-2.40)$ & 0.0094 \\
\hline $5-9$ & $54(7.9)$ & 626 & 680 & $2.43(1.71-3.45)$ & 0.0000 \\
\hline$\geq 10$ & $54(9.5)$ & 513 & 567 & $2.97(2.09-4.21)$ & 0.0000 \\
\hline $\begin{array}{l}\text { Mean number of lifetime sexual } \\
\text { partners per category }\end{array}$ & 2.9 & 1.7 & 2.3 & $\begin{array}{c}\text { Difference (those positive vs } \\
\text { those negative): } 1.2\end{array}$ & $\begin{array}{c}0.02 \\
(t=2.518)\end{array}$ \\
\hline \multicolumn{6}{|l|}{ Ever been pregnant } \\
\hline Yes & $115(3.8)$ & 2,896 & 3,011 & 1 Reference & - \\
\hline No & $251(6.3)$ & 3,707 & 3,958 & $1.71(1.36-2.14)$ & 0.0000 \\
\hline Total & $366(5.2)$ & 6,603 & 6,969 & - & - \\
\hline
\end{tabular}

$\mathrm{Cl}$ : confidence interval.

a Unless otherwise indicated.

${ }^{b}$ Where relevant. The t-test compares the mean values for women who tested positive for $C$. trachomatis and those who were negative.

c Not statistically significant. 


\section{FIGURE}

Prevalence of Chlamydia trachomatis infection in women tested at the Cervico-Vaginal Pathology Unit, Sapienza University, Rome, Italy, 2000-2009 (n=6,969)

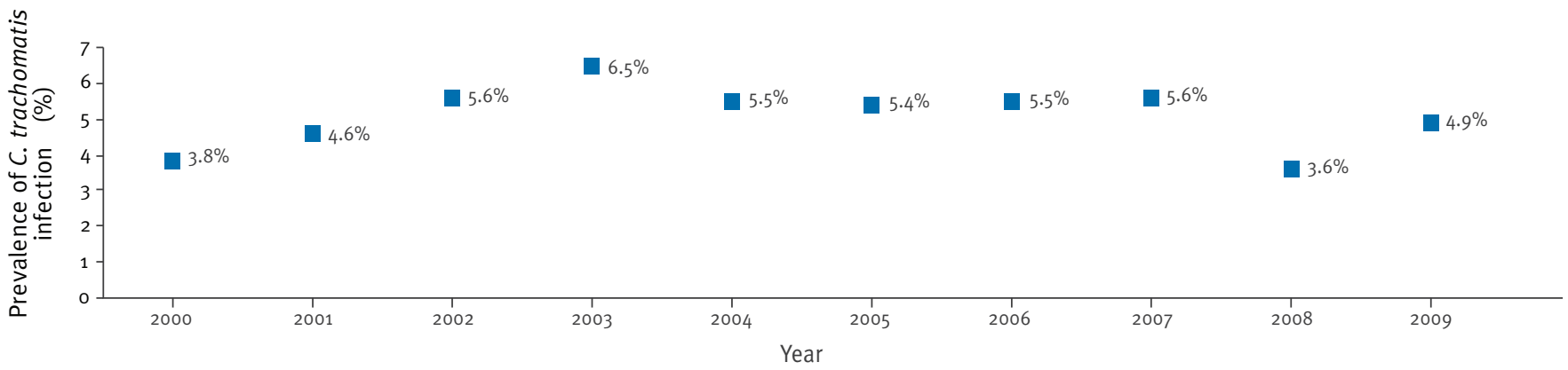

The overall chi-square statistic was 6.255 (the chi-square test for the resulting $2 \times 10$ contingency table tested the null hypothesis of no association against the alternative hypothesis of an association of some sort). The $p$ value for the chi-square statistic ( $\mathrm{p}=0.938$ ) was not statistically significant.

\section{TABLE 2}

Univariate analysis of reasons for seeking care, clinical features, contraceptive use and smoker status of 6,969 women attending as outpatients the Cervico-Vaginal Pathology Unit, Sapienza University, Rome, Italy, 2000-2009

\begin{tabular}{|c|c|c|c|c|c|}
\hline \multirow[b]{2}{*}{ Characteristic } & \multicolumn{3}{|c|}{ Tested for Chlamydia trachomatis infection } & \multirow[b]{2}{*}{ Odds ratio $(95 \% \mathrm{Cl})$} & \multirow[b]{2}{*}{$P$ value } \\
\hline & $\begin{array}{c}\text { Number } \\
\text { positive (\%) }\end{array}$ & $\begin{array}{l}\text { Number } \\
\text { negative }\end{array}$ & Total & & \\
\hline \multicolumn{6}{|c|}{ Reason for seeking care } \\
\hline Gynaecological & $207(5.3)$ & 3,666 & 3,873 & 1 Reference & - \\
\hline Infertility & $68(4.9)$ & 1,331 & 1,399 & $0.90(0.68-1.20)$ & $0.4852^{\mathrm{a}}$ \\
\hline Obstetrics & $50(5.3)$ & 889 & 939 & $1.00(0.73-1.37)$ & $0.9806^{\mathrm{a}}$ \\
\hline Family planning & $41(5.4)$ & 717 & 758 & $1.01(0.72-1.43)$ & $0.9427^{\mathrm{a}}$ \\
\hline \multicolumn{6}{|c|}{ Symptoms of $C$. trachomatis infection ${ }^{c}$} \\
\hline Yes & $110(4.7)$ & 2,239 & 2,349 & $1.19(0.95-1.50)$ & $0.1289^{\mathrm{a}}$ \\
\hline No & $256(5.5)$ & 4,364 & 4,620 & 1 Reference & - \\
\hline \multicolumn{6}{|c|}{ Signs of $C$. trachomatis infection ${ }^{d}$} \\
\hline Yes & $128(4.8)$ & 2,513 & 2,641 & $1.14(0.92-1.42)$ & $0.2362^{\mathrm{a}}$ \\
\hline No & $238(5.5)$ & 4,090 & 4,328 & 1 Reference & - \\
\hline \multicolumn{6}{|l|}{ Contraceptive use } \\
\hline None & $269(5.1)$ & 5,025 & 5,294 & 1 Reference & - \\
\hline Oral contraceptives & $43(7.3)$ & 546 & 589 & $1.47(1.05-2.05)$ & 0.0226 \\
\hline Intrauterine device & $20(5.1)$ & 372 & 392 & $1.00(0.63-1,60)$ & $0.9856^{\mathrm{a}}$ \\
\hline Condoms & $34(4.9)$ & 660 & 694 & $0.96(0.67-1.39)$ & $0.8370^{\mathrm{a}}$ \\
\hline \multicolumn{6}{|l|}{ Smoker } \\
\hline Yes & $120(6.1)$ & 1,838 & 1,958 & $1.26(1.01-1.58)$ & 0.0402 \\
\hline No & 246 (4.9) & 4,765 & 5,011 & 1 Reference & - \\
\hline Total & $366(5.2)$ & 6,603 & 6,969 & - & - \\
\hline
\end{tabular}

$\mathrm{Cl}$ : confidence interval.

${ }^{a}$ Not statistically significant.

${ }^{\text {b }}$ Dysuria or pelvic pain.

${ }^{c}$ Cervical erythema, inflammation or discharge. 
than five), have also been highlighted by research groups worldwide in various populations $[7,16,31]$. We found that the highest prevalence of infection (10.8\%) was associated with a nearly fivefold increased risk of infection (as an independent factor, it showed a twofold increased risk) in women aged 15-19 years.

Before 2008, C. trachomatis control activities in Italy consisted of case management in dermatovenereology clinics with Chlamydia testing for symptomatic people only [7]. C trachomatis testing is currently recommended for women at the time of their first cervical smear test, which takes place when women are 25 years of age in Italy. To the best of our knowledge, no report on the uptake and results of this testing recommendation is yet available. However, our data suggest that women aged under 25 years, and in particular those under 20 years, would be the core population of a good testing policy and a hypothetical $C$. trachomatis screening programme, as in other screening programmes worldwide $[7,16]$. Thus, the current Italian policy could be ineffective. The high prevalence of infection observed until the age of 40 years - which is a novel aspect of our findings - could also lead to a more extensive testing strategy. Although being aged 25-39 years was not an independent risk factor for infection, our data suggest that older women should also be tested.

Furthermore, as prevalence in women with signs or symptoms of infection did not differ statistically from that in women with no signs or symptoms in this study, case management appears to be an insufficient Chlamydia control activity.

The prevalence of infection among women seeking care for family planning was also high (5.4\%): despite the low number of women in our study who sought advice for family planning, given the high number of women who usually attend this type of service and their young age, we suggest that family planning clinics could be sentinel for Chlamydia surveillance or an appropriate setting for Chlamydia opportunistic screening.
Our data also show that having HPV or $T$. vaginalis infection was associated with a fivefold higher risk of C. trachomatis coinfection, as expected in groups at higher risk as a result of age and behaviour $[32,33]$. In our logistic regression, HPV was not significantly associated with $C$. trachomatis infection, suggesting that age and multiple partners could be possible confounding factors, while $T$. vaginalis infection was an independent risk factor for $C$. trachomatis infection. It is possible that severe inflammation of the cervix due to $T$. vaginalis infection may make the cervix more susceptible to $C$. trachomatis infection. It could therefore be suggested that patients diagnosed with $T$. vaginalis infection should be tested for $C$. trachomatis or even given treatment for $C$. trachomatis infection without being tested, as proposed by Lo et al. [33].

Data on $N$. gonorrhoeae and C. trachomatis coinfection in Italy are limited, but our findings on N. gonorrhoeae seem to be consistent with those reported in 1998 by a dermatovenereology network, which found that fewer than $1 \%$ the infections in 44,438 individuals with sexually transmitted infections were $N$. gonorrhoeae cervical infections [22].

We also found a statistical association of C. trachomatis infection with absence of previous pregnancies, use of oral contraceptives and smoking. However, as they were not shown to be statistically associated with infection in the logistic regression final model, age, having multiple lifetime sexual partners and $T$. vaginalis infection are likely to be confounders, in contrast to the findings of others [34-36].

The lack of statistical association between $C$. trachomatis infection and condom use (as a protective factor) is unexpected, given the findings of others [21,37]. This could be considered a result of incorrect condom use and lack of health education. It could also be that some of the women were not entirely truthful when providing details of the type of contraception they used. There are probably some methodological limitations in the epidemiological study of condom effectiveness in

\section{TABLE 3}

Univariate analysis of other sexually transmitted infections in 6,969 women attending as outpatients the Cervico-Vaginal Pathology Unit, Sapienza University, Rome, Italy, 2000-2009

\begin{tabular}{|l|c|c|c|c|c|}
\hline \multirow{2}{*}{$\begin{array}{l}\text { Other sexually transmitted organisms } \\
\text { detected }\end{array}$} & \multicolumn{2}{|c|}{\begin{tabular}{c} 
Tested for Chlamydia trachomatis infection \\
Number \\
\cline { 2 - 5 }
\end{tabular}} & $\begin{array}{c}\text { Number } \\
\text { nesitive (\%) }\end{array}$ & Total & \multicolumn{2}{c|}{ Odds ratio $(95 \% \mathrm{Cl})$} & P value \\
\hline Trichomonas vaginalis or HPV & $145(16.9)$ & 714 & $\mathbf{8 5 9}$ & $5.41(4.33-6.77)$ & 0.0000 \\
\hline Trichomonas vaginalis & $11(15.7)$ & 59 & $\mathbf{7 0}$ & $4.97(2.57-9.59)$ & 0.0000 \\
\hline HPV & $142(17.1)$ & 688 & $\mathbf{8 3 0}$ & $5.50(4.39-6.89)$ & 0.0000 \\
\hline Neither Trichomonas vaginalis nor HPV & $221(3.6)$ & 5,889 & $\mathbf{6 , 1 1 0}$ & 1 Reference & - \\
\hline Total & $\mathbf{3 6 6 ( 5 . 2 )}$ & $\mathbf{6 , 6 0 3}$ & $\mathbf{6 , 9 6 9}$ & - & - \\
\hline
\end{tabular}

Cl: confidence interval; HPV: human papillomavirus.

${ }^{a}$ Women coinfected with $T$. vaginalis and HPV $(n=41)$ are not included. 
preventing $C$. trachomatis infection, as has been highlighted by Warner et al. [37].

A new C. trachomatis variant was detected in 2006 following an unexpected $25 \%$ decrease in the number of infections in a Swedish county $[38,39]$. As we used the Becton Dickinson ProbeTec - which detects the new variant - the presence or absence of the variant in Italy has no impact on our prevalence data. However, as no data are available on the type and distribution of C. trachomatis diagnostic methods used in Italy, nor on whether this variant is present among Italian women, surveillance is also needed to provide such information.

In conclusion, the prevalence and determinants of $C$. trachomatis infection observed in this study seem to highlight the need for a focus on control activities in Italy, with special attention to standardisation of diagnostic tests and women aged under 25 years, who would be the core population of a screening programme.

\section{References}

1. Paavonen J. Chlamydia trachomatis infections of the female genital tract: state of the art. Ann Med. 2012;44(1):18-28.
2. World Health Organization (WHO). Prevalence and incidence of selected sexually transmitted infections, Chlamydia trachomatis, Neisseria gonorrhoeae, syphilis and Trichomonas vaginalis: methods and results used by WHO to generate 2005 estimates. Geneva: WHO; 2011. Available from: http:// whqlibdoc.who.int/publications/2011/9789241502450_eng.pdf

3. van de Laar MJ, Morré SA. Chlamydia: a major challenge for public health. Euro Surveill. 2007;12(10):pii=735. Available from: http://www.eurosurveillance.org/ViewArticle. aspx?Articleld $=735$

4. Wilson JS, Honey E, Templeton A, Paavonen J, Mårdh PA, StrayPedersen $B$, et al. A systematic review of the prevalence of Chlamydia trachomatis among European women. Hum Reprod Update. 2002;8:385-94.

5. European Centre for Disease Prevention and Control (ECDC). Chlamydia control in Europe. ECDC Guidance. Stockholm: ECDC; 2009. Available from: http://ecdc.europa.eu/en/ publications/Publications/0906_GUI_Chlamydia_Control_in_ Europe.pdf

6. European Centre for Disease Prevention and Control (ECDC). Sexually transmitted infections in Europe, 1990-2009. Stockholm: ECDC; 2011. Available from: http://ecdc.europa. eu/en/publications/Publications/110526_SUR_STI_in Europe_1990-2009.pdf

7. European Centre for Disease Prevention and Control (ECDC). Review of Chlamydia control activities in EU countries. Stockholm, May 2008. Technical Report. Stockholm: ECDC; 2008. Available from: http://ecdc.europa.eu/en/publications/ publications/0805_ter_review_of_chlamydia_control_ activities.pdf

8. Haggerty CL, Gottlieb SL, Taylor BD, Low N, Xu F, Ness RB. Risk of sequelae after Chlamydia trachomatis genital infection in women. J Infect Dis. 2010;201 Suppl 2:S134-55.

9. Baud D, Regan L, Greub G. Emerging role of Chlamydia and Chlamydia-like organisms in adverse pregnancy outcomes. Curr Opin Infect Dis. 2008;21(1):70-6.

10. Wagenlehner FM, Naber KG, Weidner W. Chlamydial infections and prostatitis in men. BJU Int. 2006;97(4):687-90.

11. Eley A, Pacey AA, Galdiero M, Galdiero M, Galdiero F. Can Chlamydia trachomatis directly damage your sperm? Lancet Infect Dis. 2005;5(1):53-7.

12. Gonçalves LF, Chaiworapongsa T, Romero R. Intrauterine infection and prematurity. Ment Retard Dev Disabil Res Rev. 2002;8(1):3-13.

13. Diemer T, Ludwig M, Huwe P, Hales DB, Weidner W. Influence of urogenital infection on sperm function. Curr Opin Urol. 2000;10(1):39-44.

14. Paavonen J, Eggert-Kruse W. Chlamydia trachomatis: impact on human reproduction . Hum Reprod Update. 1999;5(5):433-47.

15. Land JA, Van Bergen JE, Morré SA, Postma MJ. Epidemiology of Chlamydia trachomatis infection in women and the costeffectiveness of screening. Hum Reprod Update. 2010;16 (2):189-204.

16. Workowski KA, Berman S; Centers for Disease Control and Prevention (CDC). Sexually transmitted diseases treatment guidelines, 2010. MMWR Recomm Rep. 2010;59(RR-12):1-110.

17. Sutton MY, Sternberg M, Zaidi A, St Louis ME, Markowitz LE. Trends in pelvic inflammatory disease hospital discharges and ambulatory visits, United States, 1985-2001. Sex Transm Dis. 2005;32(12):778-84.

18. Chandra A, Martinez GM, Mosher WD, Abma JC, Jones J. Fertility, family planning, and reproductive health of U.S. women: data from the 2002 National Survey of Family Growth. Vital Health Stat 23. 2005;(25):1-160.

19. French CE, Hughes G, Nicholson A, Yung M, Ross JD, Williams $T$, et al. Estimation of the rate of pelvic inflammatory disease diagnoses: trends in England, 2000-2008. Sex Transm Dis. 2011;38(3):158-62.

20. Bender N, Herrmann B, Andersen B, Hocking JS, van Bergen J, Morgan J, et al. Chlamydia infection, pelvic inflammatory disease, ectopic pregnancy and infertility: cross-national study. Sex Transm Infect. 2011;87(7):601-8.

21. Determinants of cervical Chlamydia trachomatis infection in Italy. The Italian MEGIC Group. Genitourin.Med. 1993;69(2):123-5.

22. Giuliani M, Suligoi B, the STD Surveillance Working Group. Sentinel surveillance of sexually transmitted diseases in Italy. Euro Surveill. 1998;3(6):pii=97. Available from: http://www. eurosurveillance.org/viewarticle.aspx?articleid=97

23. Ministry of Health. Lo stato di salute delle donne in Italia. [Women's health status in Italy]. Rome: Ministry of Health; March 2008. Italian. Available from: http://www. ministerosalute.it/imgs/C_17_pubblicazioni_764_allegato.pdf 
24. World Medical Association (WMA). Declaration of Helsinki.

WMA General Assembly, Seoul, South Korea, October 2008.

World Medical Journal. 2008;54(4):122-5. Available from: http://www.wma.net/en/30publications/20journal/pdf/wmj2o. pdf

25. Italian Data Protection Authority. Linee guida in tema di fascicolo sanitario elettronico e di dossier sanitario. [Guidelines on the Electronic Health Record and the Health File]. Gazzetta Ufficiale - Serie Generale. 3 Aug 2009;178. Rome: Istituto Poligrafico e Zecca dello Stato. Italian. Summary available from: http://www.guritel.it/freesum/ARTI/2009/08/03/sommario.html; (English version available from: http://www.garanteprivacy.it/garante/doc. jsp?ID=1672821).

26. Donders GG. Definition and classification of abnormal vaginal flora. Best Pract Res Clin Obstet Gynaecol. 2007;21(3):355-73.

27. Amsel R, Totten PA, Spiegel CA, Chen KC, Eschenbach D, Holmes KK. Nonspecific vaginitis. Diagnostic criteria and microbial and epidemiologic associations. Am J Med.1983;74(1):14-22.

28. Health Protection Agency (HPA). Chlamydia trachomatis infection - testing by nucleic acid amplification tests (NAATs). UK standards for microbiology investigations. Virology. 37(3). London: HPA; 25 May 2012. Available from: http://www.hpa.org.uk/webw/HPAweb\&HPAwebStandard/ HPAweb_C/1316425069287

29. Manos MM, Ting Y, Wright DK, Lewis AJ, Broker TR, Wolinsky SM. Use of polymerase chain reaction amplification for the detection of genital human papillomaviruses. Cancer Cells 1989;7(17):209-14.

30. Barbé, G, Babolat M, Boeufgras IM, Monget D, Freney J. Evaluation of API NH, a new 2-hour system for identification of Neisseria and Haemophilus species and Moraxella catarrhalis in a routine clinical laboratory. J Clin Microbiol. 1994;32(1):187-9.

31. Franceschi S, Smith JS, van den Brule A, Herrero R, Arslan A, Ahn PT, et al. Cervical infection with Chlamydia trachomatis and Neisseria gonorrhoeae in women from ten areas in four continents. Sex Transm Dis. 2007;34(8):563-9.

32. Griffiths V, Cheung WH, Carlin EM, Ahmed-Jushuf I. Incidence of concurrent sexually transmitted infections in patients with genital warts. Int J STD AIDS. 2006;17(6):413-4.

33. Lo M, Reid M, Brokenshire M. Epidemiological features of women with trichomoniasis in Auckland sexual health clinics: 1998-99. New Zeal Med J. 2002;115(1159):U119.

34. Gall SA. Oral contraceptives and Chlamydia infections. JAMA. 1986;255(1):38-9.

35. Oh MK, Feinstein RA, Soileau EJ, Cloud GA, Pass RF. Chlamydia trachomatis cervical infection and oral contraceptive use among adolescent girls. J Adolesc Health Care. 1989;10(5):376-81.

36. Corbeto EL, Lugo R, Martró E, Falguera G, Ros R, Avecilla A, et al. Epidemiological features and determinants for Chlamydia trachomatis infection among women in Catalonia, Spain. Int J STD AIDS. 2010;21(10):718-22.

37. Warner L, Stone KM, Macaluso M, Buehler JW, Austin HD. Condom use and risk of gonorrhea and Chlamydia: a systematic review of design and measurement factors assessed in epidemiologic studies. Sex Transm Dis. 2006;33(1):36-51.

38. Ripa T, Nilsson PA. A variant of Chlamydia trachomatis with deletion in cryptic plasmid: implications for use of PCR diagnostic tests. Euro Surveill. 2006; Euro Surveill. 11(45):pii=3076. Available from: http://www.eurosurveillance. org/ViewArticle.aspx?Articleld $=3076$

39. Herrmann B. A new genetic variant of Chlamydia trachomatis. Sex Transm Infect. 2007; 83(4):253-4 